\title{
ASPECTOS DA FORMAÇÃO DO PESQUISADOR PARA O CAMPO DA POLÍTICA EDUCACIONAL NA PÓS-GRADUAÇÃO NO BRASIL*
}

\author{
JefFerson Mainardes ${ }^{1}$ (1) \\ Silvana STREMEL ${ }^{2}$ @
}

\begin{abstract}
RESUMO: $\mathrm{O}$ artigo apresenta os principais resultados de um estudo exploratório sobre a formação de pesquisadores para o campo da Política Educacional. A pesquisa foi realizada por meio de questionário online respondido por 108 egressos de doutorado, de linhas de pesquisa (LP) relacionadas à Política Educacional, de Programas de Pós-Graduação em Educação (PPGE). A análise dos dados fundamenta-se em aspectos da teoria de Basil Bernstein. O texto discorre ainda sobre implicaçóes e desafios para o processo de formação de pesquisadores de Política Educacional.
\end{abstract}

Palavras-chave: Política educacional. Formação de pesquisadores. Basil Bernstein.

\section{ASPECTS OF RESEARCHER TRAINING IN EDUCATION POLICY FIELD AT POSTGRADUATE LEVEL IN BRAZIL}

ABSTRACT: The article presents the main results of an exploratory study of researcher training in the field of Education Policy. The research was carried out through an online questionnaire which was fulfilled by 108 former PhD students of Postgraduate Programs in Education (Brazil). Data analysis is informed by aspects of Basil Bernstein's theory. It also presents implications for and challenges to the researcher training in Education Policy.

Keywords: Education policy. Researcher training. Basil Bernstein.

\footnotetext{
*Pesquisa parcialmente financiada pelo Conselho Nacional de Desenvolvimento Científico e Tecnológico $(\mathrm{CNPq})$ - projeto A Produção de Conhecimento Acadêmico em Política Educacional: uma Análise a partir dos Grupos de Pesquisa Cadastrados no CNPq (Processo no 304390/2015-1). ${ }^{1}$ Universidade Estadual de Ponta Grossa - Ponta Grossa (PR), Brasil. E-mail: jefferson.m@uol.com.br ${ }^{2}$ Universidade Tecnológica Federal do Paraná - Curitiba (PR), Brasil. E-mail: silvanastremel@gmail.com DOI: $10.1590 / \mathrm{ES} 0101-73302019203826$
} 


\title{
ASPECTOS DE LA FORMACIÓN DEL INVESTIGADOR PARA EL CAMPO DE LA POLÍTICA EDUCACIONAL EN EL POSGRADO EN BRASIL
}

\begin{abstract}
RESUMEN: El artículo presenta los principales resultados de un estudio exploratorio sobre la formación de investigadores para el campo de la Política Educacional. La investigación fue realizada por medio de cuestionario online respondido por 108 egresados de doctorado, de líneas de investigación (LI) relacionadas a la Política Educacional, de Programas de Posgrado en Educación (PPGE). El análisis de los datos se fundamenta en aspectos de la teoría de Basil Bernstein. El texto discurre incluso sobre implicaciones y desafíos para el proceso de formación de investigadores de Política Educacional.
\end{abstract}

Palabras clave: Política educacional. Formación de investigadores. Basil Bernstein.

\section{Introdução}

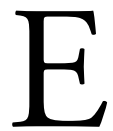

ste artigo tem por objetivo apresentar os resultados de uma pesquisa realizada com egressos de Programas de Pós-Graduação em Educação

(PPGE) brasileiros que concluíram o doutorado no período de 2013 a 2016, bem como desenvolver teorizaçóes sobre o processo de formação de pesquisadores para a área da Política Educacional. A pesquisa de campo envolveu a aplicação de um questionário online para egressos de linhas de pesquisa (LP) relacionadas à Política Educacional. A opção por realizá-la com egressos do doutorado baseia-se no fato de que este é o nível mais elevado da formação de pesquisadores. Além disso, no Brasil, a pós-graduação tem sido um dos mais importantes lócus do desenvolvimento de pesquisas e de formação de pesquisadores.

O texto apresenta uma breve contextualização da formação de pesquisadores como objeto de estudo, seguida de referencial teórico, metodologia, análise de dados e conclusóes.

\section{A formação de pesquisadores no doutorado como objeto de estudo}

Merga (2018) conceitua formação de pesquisadores educacionais como o processo pelo qual os indivíduos adquirem as habilidades e os conhecimentos necessários para conduzir pesquisas no campo da educação de modo efetivo e ético. Envolve um processo contínuo de aprendizagem para além da conclusão da formação acadêmica formal, estendendo-se ao longo da carreira como pesqui- 
sador. A formação adequada de pesquisadores educacionais é vital por conta da contribuição que a pesquisa educacional apresenta para fundamentar as políticas e as práticas pedagógicas em escolas, faculdades e universidades (MERGA, 2018).

No Brasil, a pesquisa sobre a formação de pesquisadores na pós-graduação, principalmente no doutorado, é ainda escassa (HOSTINS, 2006, 2013; PATRUS \& LIMA, 2014). No cenário internacional, há um significativo número de publicaçôes a respeito do papel do doutorado na formaçáo de pesquisadores, das culturas de pesquisa e formação, das habilidades essenciais na formação do pesquisador, da importância da avaliação do ensino e da formação de pesquisadores na pós-graduação, entre outros aspectos relevantes (DEEM \& BREHONY, 2000; MOWBRAY \& HALSE, 2010; CROSSOUARD, 2010, 2013). Um aspecto importante abordado na literatura internacional é que o futuro da pesquisa de um determinado campo está estreitamente relacionado aos espaços e às condiçóes da formação de pesquisadores, sendo necessário investigar os processos formativos, bem como propor alternativas para a melhoria permanente da formação. Alguns autores destacam que o crescente interesse pelo doutorado pode estar relacionado à importância dada à economia do conhecimento (knowledge economy), à prioridade atribuída ao desenvolvimento de uma força de trabalho altamente qualificada para a pesquisa e à relevância do doutorado para a empregabilidade e para o desenvolvimento científico do país (CROSSOUARD, 2013).

No que se refere à formaçáo de pesquisadores para o campo específico de Política Educacional, a literatura é também escassa (TELLO, 2015a; GOROSTIAGA, 2017). Constata-se, assim, que se trata de uma área de pesquisa bastante recente e ainda a ser explorada.

O interesse pela investigação dessa temática está relacionado à vinculação dos autores com a Red de Estudios Teóricos y Epistemológicos em Política Educativa (Relepe) ${ }^{1}$, criada em 2010 e que tem por objetivo desenvolver pesquisas sobre aspectos teórico-epistemológicos da pesquisa em Política Educacional.

Neste artigo, assumimos a perspectiva de que a Política Educacional constitui um campo acadêmico ${ }^{2}$ em permanente construção. No Brasil, ela desenvolveu-se como objeto autônomo de investigação a partir da década de 1960, tendo suas origens na Administração Escolar e Educacional. A partir da década de 1980, a área expandiu-se e afirmou-se como específica. Além disso, destacamos que as pesquisas sobre ela são necessárias e podem trazer elementos que podem ser reinvestidos nela mesma, objetivando o seu contínuo fortalecimento e expansão (STREMEL, 2016; MAINARDES, 2017, 2018a).

\section{Referencial teórico}

Deem e Brehony (2000), ao teorizarem sobre o conceito de cultura de formação para a pesquisa, consideram que os programas de pós-graduação (PPG) 
têm o papel de oferecer uma formação extensiva para a pesquisa. Em termos gerais, há programas que se baseiam em uma cultura de formação mais individualizada, enquanto outros se articulam em torno de disciplinas e atividades comuns ou ainda se constituem em programas integrados de pesquisa, estruturados em torno de uma legítima cultura de formaçáo para pesquisa. A existência de uma cultura de pesquisa forte e estruturada é valorizada tanto por agências de fomento e patrocinadores de pesquisas quanto por estudiosos da formação de pesquisadores. Os autores destacam também que as culturas de pesquisa e formação de pesquisadores diferem de uma área para outra (e de um contexto para outro).

No Brasil, os PPG possuem elevada autonomia para definirem seus currículos. De modo geral, os programas possuem disciplinas convencionais e seminários (como atividades obrigatórias e/ou optativas). Gradualmente, em virtude da proposição de organizar os PPG em áreas de concentração e LP (pela Coordenação de Aperfeiçoamento de Pessoal de Nível Superior - Capes), da criação do Diretório de Grupos de Pesquisa (Conselho Nacional de Desenvolvimento Científico e Tecnológico - CNPq), bem como do próprio processo de institucionalização e amadurecimento da pesquisa no país, cada vez mais se observa a existência de uma cultura de formação de pesquisadores mais integrada e articulada. Nesse contexto, as LP e os grupos de pesquisa (GP) têm adquirido papel essencial no processo de formação de pesquisadores e na orientação das pesquisas de discentes e docentes.

Alguns aspectos da teoria de Bernstein (1998) contribuem para a análise dos processos de produção do conhecimento e da formação de pesquisadores. Ao discorrer sobre a chamada "nova economia oficial da investigação" e sua relação com os métodos de investigação, Bernstein (1998) lança luzes importantes para a compreensão do processo de pesquisa. Segundo ele, no contexto inglês, a partir do fim dos anos 1980, pela influência de órgãos oficiais de fomento, as bolsas foram vinculadas ao que foi definido, dogmaticamente, como formação para a "investigação eficaz". A nova economia do financiamento passou a exercer uma pressão competitiva sobre os beneficiários para produzir mais com menos recursos. Nesse tipo de regime, o tempo é fundamental e influi na forma de coletar os dados e analisá-los.

A dependência da pesquisa dos contratos com o governo pode limitá-la ao utilizar amostras muito ajustadas ou desenhos metodológicos muito rígidos. Para Bernstein, o novo desenho do doutorado tornou-se "uma permissão para dirigir e não uma licença para explorar, investigar” (BERNSTEIN, 1998, p. 160), o que tem consequências incalculáveis para os métodos, pois tanto o estudante como os professores procurarão, por todos os meios, terminar dentro do prazo estabelecido. As análises de Bernstein referem-se ao contexto inglês, a partir da década de 1980, fortemente marcado pelo neoliberalismo e, posteriormente, pelo gerencialismo. Desde então, a obtenção de recursos para a pesquisa tornou-se, crescentemente, bastante competitiva.

No contexto brasileiro, a maior parte dos estudantes de doutorado estão em universidades públicas ${ }^{3}$, os professores que integram os PPGE são efetivos e têm 
estabilidade no emprego e o mínimo de publicaçóes exigidas é razoável. No entanto, as explicaçóes de Bernstein sobre a nova economia da investigação podem servir de alerta diante dos questionamentos acerca da gratuidade da pós-graduação nas universidades públicas e dos avanços da mercantilização da oferta educacional no Brasil.

Ademais, contribui para fundamentar a hipótese de que o pesquisador não é um mero técnico que coleta e analisa dados. Assumimos o pressuposto fundamental de que este necessita de uma formação que permita a aquisição do habitus científico ${ }^{4}$, que inclui o domínio de fundamentos teórico-epistemológicos dos principais enfoques de produçáo de conhecimento da área específica e das questôes metodológicas, éticas e políticas envolvidas no processo de pesquisa.

Uma segunda contribuição do teórico refere-se ao papel que ele atribui à teoria no processo de pesquisa. Bernstein (1998), ao fazer um balanço da sua trajetória de 35 anos pesquisa, diz que a teoria, por mais primitiva que seja, sempre vem antes da pesquisa. No momento em que se inicia uma pesquisa concreta, "a teoria já foi submetida a um esclarecimento conceitual quando colocada em relaçáo a um problema empírico; e, quando finaliza a investigaçáo concreta, novos desenvolvimentos conceituais são realizados" (BERNSTEIN, 1998, p. 121). Assim, depreende-se que a formação do pesquisador demanda o domínio amplo e consistente das teorias que fundamentam as pesquisas em um determinado campo, bem como das disputas conceituais e ideológicas existentes.

No ensaio no qual desenvolve os conceitos de discurso vertical e horizontal, Bernstein (1999) apresenta os conceitos de gramáticas forte e fraca, dentro de estruturas de conhecimento horizontais. Para ele, as teorias de gramática fraca são constituídas por linguagens paralelas, produzidas por diversos autores e que contêm fraco poder de conceptualização. Já as teorias de gramática forte possuem uma sintaxe conceitual explícita que permite descriçôes empíricas relativamente precisas e sem ambiguidades e/ou de gerar modelos formais de relaçóes empíricas. Bernstein (1999) considera a Sociologia, a Antropologia e os Estudos Culturais como exemplos de gramáticas fracas e a Economia, a Linguística e as áreas da Psicologia como exemplos de gramáticas fortes.

Morais (2004) explica que a ciência da educação é uma estrutura de conhecimento fundamentalmente horizontal, caracterizada por gramáticas fracas, isto é, uma estrutura de conhecimento caracterizada por linguagens paralelas, produzida por diversos autores e que contém fraco poder de conceptualizaçáo. Esse fato dificulta às teorias educacionais originar uma linguagem externa de descriçáo e uma atividade empírica com uma estruturação segura (MORAIS, 2004). Uma inferência possível com base nesses conceitos é que o processo de formação de pesquisadores necessita instrumentalizar os futuros pesquisadores com o domínio teórico-epistemológico sólido para que sejam capazes de distinguir as matrizes epistemológicas, identificar o potencial dos discursos vertical e horizontal e das teorias (fortes e fracas) e definir o referencial teórico de modo consciente e reflexivo 5 . 
Em terceiro lugar, Bernstein (1998) faz uma distinção conceitual entre os modelos pedagógicos de competência e de desempenho. A lógica social de um modelo de competência tem uma visão do sujeito como ativo, criativo e autorregulador. Um modelo de competência é voltado para dentro, na medida em que se concentra no desenvolvimento do indivíduo e, portanto, de uma identidade introjetada (voltada para o interior); ao prometer uma "democracia universal de aquisição" (BERNSTEIN, 2003, p. 78), reflete a possibilidade de emancipação. Em contraste, o modelo de desempenho de Bernstein desloca a atençáo para os textos ou resultados que se espera que o adquirente desenvolva ou as habilidades especializadas que eles devem desenvolver (BERNSTEIN, 1998).

Enquanto um modelo de competência é terapêutico na maneira como ele direciona a atenção para o indivíduo, um de desempenho é visto como atendendo principalmente aos objetivos econômicos e, portanto, é considerado instrumental, logo, uma identidade projetada (voltada para o exterior, ao invés de uma identidade introjetada). Em seu modelo de desempenho, Bernstein (1998) faz a distinção entre os singulares, as regiōes e os modos genéricos de produção de conhecimento. Essas distinções são feitas considerando a força da classificação que lhes permite ser reconhecido como distintivo.

O conceito de classificação tem um significado bernsteiniano particular, na medida em que incide sobre a força do isolamento que permite que determinadas categorias sejam entendidas como distintas. Em uma classificação forte, as disciplinas e áreas são vistas como separadas. A regionalização reflete uma classificação mais fraca, evidenciando a emergência de novas interfaces entre campos intelectuais de produção de conhecimento e campos de prática. Os modos genéricos e os desempenhos que eles originam estâo diretamente ligados às instrumentalidades do mercado, à construção daquilo que é considerado desempenho flexível.

Aplicando esses conceitos ao processo de formaçáo de pesquisadores, constata-se que, muitas vezes, enfatiza-se o modelo de desempenho, por meio de classificaçôes fortes (poucas relaçôes interdisciplinares na formação) e estratégias de controle explícitos (prazos, metas a serem alcançadas) e com baixo custo (fazer mais com menos recursos, mesmo que a formaçáo se torne mais aligeirada). Nesse modelo, criam-se identidades projetadas (diretamente ligadas ao campo da economia e, por isso, com uma maior dependência externa). A projeção traduz-se, assim, numa posição utilitária, baseada nas exigências de mercado.

O modelo de competência, por sua vez, possui um custo mais elevado, visto que demanda maior tempo e maior investimento para a pesquisa e para a formação. No modelo de competência, as classificaçóes são fracas (com fortes relaçóes intra e interdisciplinares) e a autonomia dos estudantes é bastante valorizada (identidades projetadas). Ainda que o domínio de técnicas de pesquisa seja valorizado, um modelo pedagógico de competência compromete-se mais intensamente com o desenvolvimento de habilidades intelectuais e cognitivas que são essenciais 
para o trabalho acadêmico. As identidades introjetadas sáo associadas a projetos pessoais, em que o conceito de eu passa a ser fundamental. A introjeção pode, dessa maneira, traduzir-se num sentimento de lealdade para com uma determinada disciplina (campo) ou num compromisso associado a um projeto pessoal.

Com base nesses pressupostos teóricos, pode-se argumentar que as culturas de pesquisa e de formação de pesquisadores são processos históricos e variam conforme o contexto, a área, a época e as tradiçóes de pesquisa. Embora a formação de pesquisadores para o campo da Política Educacional, no doutorado, se dê dentro de um contexto nacional e global, possui especificidades a serem exploradas. Além disso, a partir de contribuiçóes da teoria de Bourdieu (2011), destaca-se que as pesquisas sobre o próprio campo são importantes e podem trazer elementos que podem ser reinvestidos nele mesmo, objetivando a compreensão do seu funcionamento, bem como seu contínuo fortalecimento e expansão.

\section{Metodologia}

A pesquisa envolveu a aplicação de um questionário online para egressos de PPGE brasileiros que concluíram o doutorado no período de 2013 a 2016. As etapas da pesquisa foram as seguintes:

- Levantamento dos PPGE que ofertavam doutorado e possuíam LP relacionadas à Política Educacional na Plataforma Sucupira, da Capes;

- Levantamento dos nomes dos docentes que integravam as LP relacionadas à Política Educacional a partir da consulta aos sites dos PPGE;

- Levantamento das teses orientadas pelos docentes das LP dos PPGE a partir de consulta ao Currículo Lattes dos docentes;

- Localização do e-mail dos egressos dos PPGE e envio do convite para responder ao questionário online. Além disso, o convite para participar da pesquisa foi enviado também a partir do espaço de contato disponível no Currículo Lattes;

- $\quad$ Análise de dados.

Segundo dados da Capes, no ano de 2016, o Brasil contava com 170 PPGE - 130 acadêmicos e 40 de mestrado profissional. Do total de 170 programas acadêmicos, 74 ofereciam mestrado e doutorado e 54, apenas mestrado. Dos 130 acadêmicos, 90 contavam com LP relacionada à Política Educacional (69\%), enquanto 16 dos 40 mestrados profissionais (43\%) apresentavam LP desse campo. Dos 74 programas (mestrado e doutorado), constatou-se que em 53 houve concluintes de doutorado no período. O Quadro 1 apresenta o total de 


\section{Quadro 1}

Número de teses das linhas de Pesquisa de Política Educacional (doutorado) e número de teses de Política Educacional (2013-2016).

\begin{tabular}{|c|c|c|c|c|}
\hline No & Instituiçáo & Linha de pesquisa & $\begin{array}{c}\text { No } \\
\text { total de } \\
\text { teses da } \\
\text { linha }\end{array}$ & $\begin{array}{l}\text { No de } \\
\text { teses } \\
\text { de PE }\end{array}$ \\
\hline 1 & $\begin{array}{l}\text { Universidade Federal } \\
\text { do Paraná (UFPR) }\end{array}$ & Políticas Educacionais & 25 & 25 \\
\hline 2 & Universidade de São Paulo (USP) & Estado, Sociedade e Educação & 37 & 18 \\
\hline 3 & $\begin{array}{l}\text { Pontifícia Universidade Católica } \\
\text { do Paraná (PUC-PR) }\end{array}$ & História e Políticas da Educação & 27 & 17 \\
\hline 4 & $\begin{array}{l}\text { Universidade Estadual de } \\
\text { Campinas (UNICAMP) }\end{array}$ & $\begin{array}{l}\text { Estado, Políticas Públicas e } \\
\text { Educação }\end{array}$ & 27 & 16 \\
\hline 5 & $\begin{array}{l}\text { Universidade Estadual Paulista } \\
\text { "Júlio de Mesquita Filho" } \\
\text { (UNESP), campus de Marília }\end{array}$ & $\begin{array}{l}\text { Políticas Educacionais, Gestão } \\
\text { de Sistemas e Organizaçôes, } \\
\text { Trabalho e Movimentos Sociais }\end{array}$ & 18 & 16 \\
\hline \multirow[b]{2}{*}{6} & \multirow{2}{*}{$\begin{array}{l}\text { Universidade Federal } \\
\text { de Minas Gerais (UFMG) }\end{array}$} & Políticas Públicas de Educação & 9 & 9 \\
\hline & & $\begin{array}{l}\text { Política, Trabalho e Formação } \\
\text { Humana }\end{array}$ & 27 & 6 \\
\hline 7 & $\begin{array}{l}\text { Universidade Federal } \\
\text { do Pará (UFPA) }\end{array}$ & Políticas Públicas Educacionais & 18 & 15 \\
\hline 8 & Universidade de Brasília (UnB) & $\begin{array}{l}\text { Políticas Públicas e Gestão da } \\
\text { Educação }\end{array}$ & 19 & 14 \\
\hline 9 & $\begin{array}{l}\text { Universidade Federal do } \\
\text { Rio Grande do Sul (UFRGS) }\end{array}$ & $\begin{array}{l}\text { Políticas e Gestão de Processos } \\
\text { Educacionais }\end{array}$ & 14 & 14 \\
\hline 10 & $\begin{array}{l}\text { Pontifícia Universidade Católica } \\
\text { do Rio de Janeiro (PUC-Rio) }\end{array}$ & $\begin{array}{l}\text { Educação, Desigualdades Sociais } \\
\text { e Políticas Públicas }\end{array}$ & 13 & 13 \\
\hline 11 & $\begin{array}{l}\text { Universidade Federal de } \\
\text { Juiz de Fora (UFJF) }\end{array}$ & $\begin{array}{l}\text { Gestão, Políticas Públicas e } \\
\text { Avaliaçáo Educacional }\end{array}$ & 18 & 12 \\
\hline 12 & $\begin{array}{l}\text { Universidade Federal do } \\
\text { Rio de Janeiro (UFRJ) } \\
\end{array}$ & $\begin{array}{l}\text { Políticas e Instituiçōes } \\
\text { Educacionais }\end{array}$ & 15 & 12 \\
\hline 13 & $\begin{array}{l}\text { Universidade Federal do } \\
\text { Rio Grande do Norte (UFRN) } \\
\end{array}$ & $\begin{array}{l}\text { Educação, Política e Práxis } \\
\text { Educativas }\end{array}$ & 14 & 12 \\
\hline 14 & $\begin{array}{l}\text { Universidade Federal } \\
\text { de Pernambuco (UFPE) }\end{array}$ & $\begin{array}{l}\text { Política Educacional, } \\
\text { Planejamento e Gestão da } \\
\text { Educação } \\
\end{array}$ & 12 & 11 \\
\hline 15 & $\begin{array}{l}\text { Pontifícia Universidade Católica } \\
\text { de São Paulo (PUC-SP) }\end{array}$ & $\begin{array}{l}\text { Políticas Públicas e Reformas } \\
\text { Educacionais e Curriculares }\end{array}$ & 21 & 10 \\
\hline 16 & $\begin{array}{l}\text { Universidade Federal de } \\
\text { Mato Grosso do Sul (UFMS) }\end{array}$ & História, Políticas e Educação & 14 & 10 \\
\hline 17 & $\begin{array}{l}\text { Pontifícia Universidade Católica } \\
\text { de Goiás (PUC-Goiás) }\end{array}$ & $\begin{array}{l}\text { Estado, Políticas e Instituiçóes } \\
\text { Educacionais }\end{array}$ & 12 & 10 \\
\hline 18 & $\begin{array}{l}\text { Universidade Federal } \\
\text { de Goiás (UFG) }\end{array}$ & $\begin{array}{l}\text { Estado, Políticas e História da } \\
\text { Educação }\end{array}$ & 10 & 10 \\
\hline
\end{tabular}

Continua... 


\section{Quadro 1}

Continuação.

\begin{tabular}{|c|c|c|c|c|}
\hline No & Instituiçáoo & Linha de pesquisa & $\begin{array}{c}\text { No } \\
\text { total de } \\
\text { teses da } \\
\text { linha } \\
\end{array}$ & $\begin{array}{l}\text { No de } \\
\text { teses } \\
\text { de PE }\end{array}$ \\
\hline 19 & $\begin{array}{l}\text { Universidade do Vale do } \\
\text { Rio dos Sinos (UNISINOS) }\end{array}$ & Educação, História e Políticas & 15 & 9 \\
\hline 20 & $\begin{array}{l}\text { Universidade Federal } \\
\text { da Bahia (UFBA) }\end{array}$ & Política e Gestão da Educação & 11 & 9 \\
\hline 21 & $\begin{array}{l}\text { Universidade Federal } \\
\text { Fluminense (UFF) }\end{array}$ & $\begin{array}{l}\text { Políticas, Educação, Formação e } \\
\text { Sociedade }\end{array}$ & 13 & 8 \\
\hline 22 & $\begin{array}{l}\text { Universidade Estadual Paulista } \\
\text { "Júlio de Mesquita Filho" (UNESP), } \\
\text { campus de Araraquara }\end{array}$ & Política e Gestão Educacional & 22 & 7 \\
\hline 23 & $\begin{array}{l}\text { Universidade Nove } \\
\text { de Julho (UNINOVE) }\end{array}$ & Políticas Educacionais & 31 & 6 \\
\hline 24 & $\begin{array}{l}\text { Universidade Federal } \\
\text { de Sáo Carlos (UFSCar) }\end{array}$ & $\begin{array}{l}\text { Estado, Política e Formação } \\
\text { Humana }\end{array}$ & 19 & 6 \\
\hline 25 & $\begin{array}{l}\text { Universidade Federal } \\
\text { do Piauí (UFPI) }\end{array}$ & $\begin{array}{l}\text { Educação, Movimentos Sociais e } \\
\text { Políticas Públicas }\end{array}$ & 12 & 6 \\
\hline 26 & $\begin{array}{l}\text { Universidade Tuiuti } \\
\text { do Paraná (UTP) }\end{array}$ & $\begin{array}{l}\text { Políticas Públicas e Gestão da } \\
\text { Educaçấo }\end{array}$ & 11 & 6 \\
\hline 27 & $\begin{array}{l}\text { Universidade Estadual } \\
\text { de Maringá (UEM) }\end{array}$ & Políticas e Gestão em Educação & 8 & 6 \\
\hline 28 & $\begin{array}{l}\text { Universidade Federal } \\
\text { de berlândia (UFU) }\end{array}$ & $\begin{array}{l}\text { Estado, Políticas e Gestão da } \\
\text { Educação }\end{array}$ & 7 & 6 \\
\hline 29 & $\begin{array}{l}\text { Pontifícia Universidade Católica } \\
\text { do Rio Grande do Sul (PUC-RS) }\end{array}$ & $\begin{array}{l}\text { Formação, Políticas e Práticas em } \\
\text { Educaçáo }\end{array}$ & 25 & 5 \\
\hline 30 & $\begin{array}{l}\text { Universidade Estadual de } \\
\text { Ponta Grossa (UEPG) }\end{array}$ & História e Políticas Educacionais & 11 & 5 \\
\hline 31 & $\begin{array}{l}\text { Universidade Estadual Paulista } \\
\text { "Júlio de Mesquita Filho" (UNESP), } \\
\text { campus de Presidente Prudente }\end{array}$ & $\begin{array}{l}\text { Formação dos Profissionais da } \\
\text { Educação, Políticas Educativas e } \\
\text { Escola Pública }\end{array}$ & 10 & 5 \\
\hline 32 & $\begin{array}{l}\text { Universidade Federal } \\
\text { de Santa Maria (UFSM) }\end{array}$ & $\begin{array}{l}\text { Práticas Escolares e Políticas } \\
\text { Públicas }\end{array}$ & 15 & 4 \\
\hline 33 & $\begin{array}{l}\text { Universidade Federal } \\
\text { do Espírito Santo (UFES) }\end{array}$ & $\begin{array}{l}\text { Educação, Formação Humana e } \\
\text { Políticas Públicas }\end{array}$ & 14 & 4 \\
\hline 34 & $\begin{array}{l}\text { Universidade Federal } \\
\text { da Paraíba (UFPB) }\end{array}$ & Políticas Educacionais & 10 & 4 \\
\hline 35 & $\begin{array}{l}\text { Universidade Católica } \\
\text { Dom Bosco (UCDB) }\end{array}$ & $\begin{array}{l}\text { Políticas Educacionais, Gestão da } \\
\text { Escola e Formação Docente }\end{array}$ & 4 & 4 \\
\hline 36 & $\begin{array}{l}\text { Universidade do } \\
\text { Vale do Itajaí (UNIVALI) }\end{array}$ & $\begin{array}{l}\text { Políticas para a Educação Básica } \\
\text { e Superior }\end{array}$ & 4 & 4 \\
\hline 37 & $\begin{array}{l}\text { Universidade Federal } \\
\text { de Santa Catarina (UFSC) }\end{array}$ & $\begin{array}{l}\text { Educaçáo, Estado e Políticas } \\
\text { Públicas }\end{array}$ & 3 & 3 \\
\hline
\end{tabular}

Continua... 


\section{Quadro 1}

Continuação.

\begin{tabular}{|c|c|c|c|c|}
\hline No & Instituiçáo & Linha de pesquisa & $\begin{array}{l}\text { No } \\
\text { total de } \\
\text { teses da } \\
\text { linha }\end{array}$ & $\begin{array}{l}\text { No de } \\
\text { teses } \\
\text { de PE }\end{array}$ \\
\hline 38 & $\begin{array}{l}\text { Universidade Metodista } \\
\text { de Piracicaba (UNIMEP) }\end{array}$ & $\begin{array}{l}\text { Núcleo de estudos e pesquisa } \\
\text { Trabalho Docente, Formação } \\
\text { de Professores e Políticas } \\
\text { Educacionais }\end{array}$ & 13 & 2 \\
\hline 39 & $\begin{array}{l}\text { Universidade Católica } \\
\text { de Brasília (UCB) }\end{array}$ & $\begin{array}{l}\text { Política, Gestão e Economia da } \\
\text { Educação }\end{array}$ & 9 & 2 \\
\hline 40 & $\begin{array}{l}\text { Universidade Metodista } \\
\text { de São Paulo (UMESP) }\end{array}$ & Políticas e Gestão Educacionais & 7 & 2 \\
\hline \multirow{2}{*}{41} & \multirow{2}{*}{$\begin{array}{l}\text { Universidade Católica } \\
\text { de Santos (UNISANTOS) }\end{array}$} & $\begin{array}{l}\text { LP I: Formação e Profissionalização } \\
\text { Docente: Políticas e Práticas }\end{array}$ & 3 & 0 \\
\hline & & $\begin{array}{l}\text { LP II: Educação Escolar: Políticas } \\
\text { e Práticas }\end{array}$ & 4 & 1 \\
\hline 42 & $\begin{array}{l}\text { Universidade Federal } \\
\text { de Alagoas (UFAL) }\end{array}$ & História e Política da Educação & 6 & 1 \\
\hline 43 & $\begin{array}{l}\text { Universidade Estadual Paulista } \\
\text { "Júlio de Mesquita Filho" (UNESP), } \\
\text { campus de Rio Claro }\end{array}$ & $\begin{array}{l}\text { Educação: Políticas, Gestáo e o } \\
\text { Sujeito Contemporâneo }\end{array}$ & 3 & 1 \\
\hline 44 & $\begin{array}{l}\text { Universidade de } \\
\text { Passo Fundo (UPF) }\end{array}$ & Políticas Educacionais & 2 & 1 \\
\hline 45 & $\begin{array}{l}\text { Pontifícia Universidade Católica } \\
\text { de Minas Gerais (PUC Minas) }\end{array}$ & $\begin{array}{l}\text { Educação: direito à educação e } \\
\text { políticas educacionais para os } \\
\text { diferentes níveis e modalidades } \\
\text { de ensino }\end{array}$ & 1 & 1 \\
\hline 46 & $\begin{array}{l}\text { Universidade Estácio } \\
\text { de Sá (UNESA) }\end{array}$ & $\begin{array}{l}\text { Políticas, Gestão e Formação de } \\
\text { Educadores }\end{array}$ & 1 & 1 \\
\hline 47 & $\begin{array}{l}\text { Universidade } \\
\text { de Sorocaba (UNISO) }\end{array}$ & $\begin{array}{l}\text { História e Historiografia: Políticas } \\
\text { e Práticas Escolares }\end{array}$ & 8 & 0 \\
\hline 48 & $\begin{array}{l}\text { Centro Universitário } \\
\text { La Salle (UNILASALLE) }\end{array}$ & $\begin{array}{l}\text { Gestão, Educação e Políticas } \\
\text { Públicas }\end{array}$ & 3 & 0 \\
\hline 49 & $\begin{array}{l}\text { Universidade Católica } \\
\text { de Petrópolis (UCP) }\end{array}$ & $\begin{array}{l}\text { Formação e Trabalho Docentes: } \\
\text { Políticas e Práticas }\end{array}$ & 3 & 0 \\
\hline 50 & $\begin{array}{l}\text { Universidade Federal } \\
\text { do Amazonas (UFAM) }\end{array}$ & $\begin{array}{l}\text { Educação, Políticas Públicas e } \\
\text { Desenvolvimento Regional }\end{array}$ & 2 & 0 \\
\hline 51 & $\begin{array}{l}\text { Universidade Federal do Estado } \\
\text { do Rio de Janeiro (UNIRIO) }\end{array}$ & Políticas e Práticas em Educação & 1 & 0 \\
\hline 52 & $\begin{array}{l}\text { Universidade Federal Rural } \\
\text { do Rio de Janeiro (UFRRJ) }\end{array}$ & $\begin{array}{l}\text { Desigualdades Sociais e Políticas } \\
\text { Educacionais }\end{array}$ & 1 & 0 \\
\hline & TOTAL & 54 & 662 & 369 \\
\hline
\end{tabular}

PE: Política Educacional. 
teses da LP de Política Educacional e o número de teses que, após a análise, foram consideradas com temática relacionada à Política Educacional.

A seleção dos PPGE com LP relacionadas à Política Educacional baseou-se nos dados de uma pesquisa anterior (STREMEL, 2016), na qual foram coletados dados sobre todos os PPGE brasileiros (áreas de concentração, LP etc.) a partir de informação da Capes (Plataforma Sucupira) e da descrição das LP (a partir do site dos PPGE). A definição da lista de PPGE com LP relacionadas à Política Educacional envolveu a análise dos nomes das LP e da descrição de cada uma delas. A seleçâo das teses e sua aderência ao campo da Política Educacional foram realizadas a partir da análise do título e do resumo, tomando-se como parâmetro as áreas e os temas que pesquisadores do campo têm considerado que sejam os objetos de estudo da Política Educacional (TELLO, 2015b, MAINARDES, 2018b).

Um dado importante do Quadro 1 é a diferença entre os números de teses defendidas e de teses que efetivamente abordavam questôes de Política Educacional. No período de 2013-2016, foram defendidas 663 teses, sendo que 369 (55,65\%) tratavam de temas diretamente relacionados à Política Educacional. Esses dados indicam que as LP são abrangentes e abarcam uma série de temáticas para além da Política Educacional. No Brasil, as LP de Política Educacional estão relacionadas a outras áreas, tais como Gestão, História da Educação, Avaliação, movimentos sociais, direito à educação, currículo, formação de professores etc. ${ }^{6}$.

Os PPGE que concentraram maior número de concluintes, com teses mais fortemente articuladas às temáticas do campo da Política Educacional, em ordem decrescente, foram: Universidade Federal do Paraná (UFPR); Universidade de São Paulo (USP); Pontifícia Universidade Católica do Paraná (PUCPR); Universidade Estadual de Campinas (UNICAMP); Universidade Estadual Paulista "Júlio de Mesquita Filho" (Unesp), campus de Marília; Universidade Federal do Pará (UFPA); Universidade de Brasília (UnB); Universidade Federal do Rio Grande do Sul (UFRGS); Universidade Federal de Juiz de Fora (UFJF); Universidade Federal do Rio de Janeiro (UFRJ); Universidade Federal do Rio Grande do Norte (UFRN); PUC-Rio; Universidade Federal de Pernambuco (UFPE); PUC-SP (Currículo); Universidade Federal de Santa Maria (UFSM); PUC-Goiás; e Universidade Federal de Goiás (UFG). No período pesquisado, havia 432 docentes nas LP de Política Educacional, e 219 tiveram concluintes de doutorado; 95 náo tiveram nenhum concluinte de doutorado; 90 orientavam doutorado, mas ainda não tinham nenhum concluinte; e 28 já haviam orientado doutorado, mas não tiveram nenhum concluinte no período.

Para atender aos objetivos da pesquisa, foi considerado o total de 369 egressos de doutorado cujas teses abordavam temáticas específicas de Política Educacional (a partir da análise do título e do resumo). O convite para participar da pesquisa (questionário online) foi enviado para todos os 369 egressos, tendo sido recebidas respostas de 108 deles $(29,2 \%)$. 
Com relação à idade, a maioria (38\%) dos respondentes tinha entre 31 e 40 anos; $35 \%$ tinham de 41 a 50 anos; $22 \%$, de 51 a 60 anos; $4 \%$, mais de 60 anos; e 1\%, entre 20 e 30 anos. Do total de 108 respondentes, 3\% possuíam pós-doutorado no país e $1 \%$, no exterior.

Com relação ao tempo de experiência em pesquisa, incluindo iniciação científica (graduação), mestrado e doutorado, apurou-se o seguinte quadro: 38\% com experiência de 6 a 10 anos; 37\%, de 11 a 15 anos; 16\%, de 16 a 20 anos; e $9 \%$ com mais de 20 anos.

Os respondentes realizaram o doutorado nas seguintes instituiçóes: UFPR (10 egressos); UFRGS (7); UNESP (7); UFJF (6); UFPA (6); Universidade Federal de São Carlos (UFSCar) (6); USP (6); UFRJ (5), UnB (5); UFG (4); UFPE (4); PUC-PR (3); PUC-Rio (3); PUC-RS (3); PUC-SP (3); Universidade Federal Fluminense (UFF) (3); UNICAMP (3); Universidade Católica Dom Bosco (UCDB) (2); Universidade Estadual de Maringá (UEM) (2); Universidade Federal do Ceará (UFC) (2); Universidade Federal do Mato Grosso do Sul (UFMS) (2); Universidade Federal da Paraíba (UFPB) (2); Universidade Nove de Julho (UNINOVE) (2); Universidade do Vale do Rio dos Sinos (UNISINOS) (2); Universidade Tuiuti do Paraná (UTP) (2); Universidade Estadual de Ponta Grossa (UEPG) (1); Universidade Federal da Bahia (UFBA) (1); Universidade Federal do Espírito Santo (UFES) (1); Universidade Federal de Minas Gerais (UFMG) (1); Universidade Federal do Rio Grande do Norte (UFRN) (1); Universidade Federal de Santa Catarina (UFSC) (1); UFSM (1); e Universidade do Vale do Itajaí (UNIVALI) (1). Os respondentes concluíram o doutorado nos seguintes anos: 2013 (19\%), 2014 (26\%), 2015 (32\%) e 2016 (23\%). Houve grande dispersão com relação aos orientadores, pois de 108 respondentes se apurou o total de 74 orientadores.

Com relação à participação em redes de pesquisa, 48\% afirmaram que estavam ligados a redes e GP. Dos respondentes, $82 \%$ participaram de eventos específicos de Política Educacional.

\section{Análise de dados}

A maioria dos respondentes (59\%) considerou a formação recebida como satisfatória e adequada; $38 \%$ avaliaram como bastante satisfatória; $2 \%$, insatisfatória; e apenas $1 \%$ indicou que a formação fora inexistente. Esses dados indicam que os egressos têm uma percepção positiva da formação, mas não deixaram de indicar fragilidades, lacunas e pontos fracos. As principais lacunas mencionadas referem-se à ausência de discussōes sobre aspectos teórico-metodológicos e epistemológicos (22 egressos); ausência de disciplinas e discussōes específicas de Política Educacional (14); escassez de tempo para aprofundar os estudos (6); fragilidades da trajetória acadêmica desde a graduação (3); falta de intercâmbio entre grupos de pesquisa e com pesquisadores internacionais (3); falta de discussão sobre teorias de Estados e políticas públicas (3); e fragilidades no processo de orientação (2). 
Com relação aos espaços de formação, os mais recorrentes foram: leitura e estudo individual (100 egressos); disciplinas obrigatórias (92); sessóes de orientação individual (85); reunióes do GP (81); disciplinas optativas (79); seminários oferecidos pelo programa (58); sessôes de orientação coletiva (52); seminários oferecidos pelo GP (49); e leitura e estudo em grupo (47). É interessante destacar que os respondentes indicaram outros espaços, tais como: campo empírico profissional; participação em eventos e cursos; doutorado sanduíche; encontros de discussão organizados pelos próprios alunos; e participação em projetos de pesquisa e em pesquisa interinstitucional. Observa-se que um número significativo de egressos (92) destacou a importância das disciplinas obrigatórias e optativas. As disciplinas com maior número de indicaçóes foram as sobre análise de políticas; as sobre Estado, sociedade e educaçáo; as que abordaram políticas públicas e reformas curriculares; os seminários diversos; e o seminário sobre tendências epistemológicas na pesquisa em políticas educacionais.

Embora reconhecido como um estudo exploratório e de pequena escala, os dados indicaram que a formação privilegia o desenvolvimento de habilidades mais genéricas, mas sem deixar de discorrer sobre questóes específicas de Política Educacional. Para Bernstein (1998), os modos de desempenho, pelo menos os regionalizados e os genéricos, servem a finalidades econômicas e são considerados instrumentais. O conhecimento especializado (regionalizado) de Políticas Educacionais (análise de políticas, Estado e Política Educacional etc.) nem sempre era disponibilizado para os doutorandos das LP relacionadas à área.

Uma evidência importante para respaldar esta análise foram as respostas dadas pelos participantes com relação aos elementos fundamentais da formação do pesquisador em Política Educacional. Embora essa formação seja um processo longo e que extrapola a formação recebida durante o doutorado, considerou-se que os egressos teriam contribuiçôes relevantes para a definição dos elementos fundamentais. $\mathrm{Na}$ visão deles, a formação necessita contemplar de forma mais orgânica e articulada o estudo de fundamentos teóricos para as pesquisas (49 respostas), do estudo de questôes metodológicas na pesquisa em Política Educacional (33); e de Epistemologia (geral) e epistemologias das políticas educacionais (20). No entanto, os egressos indicaram a necessidade de a formação contemplar temáticas mais específicas, tais como gestão educacional e escolar, gestão democrática, financiamento da educação, legislação, questóes éticas, currículo, história da Política Educacional, regulação, avaliação educacional, avaliação de políticas, burocracia, democracia, emancipação, público-privado, análise de conjuntura, análise de dados, políticas de avaliação e economia política.

No modelo pedagógico de competência, pode-se argumentar que se tornam altamente relevantes o estudo aprofundado das principais correntes teóricas e dos debates epistemológicos mais amplos das Ciências Sociais e Humanas, bem como do estudo de aspectos mais específicos da pesquisa em Política Educacional (TELLO \& MAINARDES, 2015). Questionados a respeito do estudo da Epistemologia, 59 respondentes (55\%) afirmaram que cursaram disciplina (ou dis- 
ciplinas) desta área e 49 responderam que não tiveram (45\%). Entre aqueles que não cursaram, diversos destacaram que esta fora "uma parte fraca na minha formação" $(\mathrm{E} 1)^{7}$. Ao contrário, aqueles que cursaram, destacaram contribuiçóes positivas:

Sim. Foi fundamental para a minha formação, pois é importante entender que há diferentes enfoques e perspectivas que podem ser usadas em uma pesquisa e que, dependendo da escolha feita pelo pesquisador, haverá um tipo de resultado na investigação (E5).

Sim. Considero que foi a disciplina mais importante da minha formaçáa como pesquisador (E6).

Sim. Foi decisiva além da orientaçáo do meu orientador (E7).

Sim. A formação epistemológica é a base para a construção argumentativa. No entanto, a disciplina, apesar de ter contribuído para minha formação teórica, năo contribuiu para as pesquisas que desenvolvo, devido à sua limitação a estudos teóricos direcionados apenas a algumas perspectivas (E23).

Sim, lógico. Na verdade, não foi muito boa, uma vez que o professor dedicou-se apenas à área do conhecimento que dominava e deixou a desejar nas outras perspectivas epistemológicas (E38).

Sim. Uma das melhores disciplinas cursadas, fundamental na formação do pesquisador, pois abordou a própria gênese da investigação científica, passando pelo positivismo, racionalismo crítico, hermenêutica e epistemologia da pesquisa educacional (E 41).

Com relação à existência de disciplinas ou discussóes sobre questóes teórico-metodológicas específicas de Política Educacional, a maioria (90\%) respondeu afirmativamente e $10 \%$, negativamente. Segundo os participantes da pesquisa, as referidas questóes foram tratadas em disciplinas convencionais do currículo (79 egressos), nas atividades realizadas nos grupos de pesquisa (63), nas sessôes de orientação (63), em seminários (58), durante o doutorado sanduíche (2), em estudos individuais (1), em rede de pesquisa (1) e em eventos (1). Entre os respondentes, ficou evidente que os egressos valorizam o estudo mais especializado do campo:

Possibilitou construir subsídios teórico-analíticos para compreensão do campo da avaliação da Educação Superior (E3).

Contribuíram na ampliação dos debates teóricos e metodológicos, nos apresentando autores diversos de forma contundente e aprofundada (E14).

Essas reflexóes me permitiram conhecer e realizar uma análise crítica dos referenciais mais utilizados na análise das políticas educacionais, quase sempre pautados nas categorias marxistas (E16). 
Em vários aspectos, mas o principal foi quanto ao desenvolvimento de minha capacidade de análise crítica quanto aos aspectos teóricos de outras pesquisas, e até mesmo nas orientaçóes das políticas educacionais (E23).

Saber diferenciar as correntes no campo da política educacional, definir conceitos, entender a influência da política externa nas políticas do nosso país (E24).

Ajudou-me a construir caminhos interpretativos sobre as políticas educacionais e também a ter segurança metodológica (E26).

Contribuíram com uma visão ampliada sobre as políticas educacionais, uma vez que eu, como professora da Educação Básica naquele período (no setor público estadual e municipal), tinha o domínio da prática, dos programas que chegavam às escolas, mas não sabia o que havia por trás deles. Isso teve relevância e ainda tem hoje como professora universitária e pesquisadora da área da Educação (E38).

Contribuíram para o diálogo de visóes diferentes, e muitas vezes conflitantes, sobre a política educacional brasileira, suas origens, modelos de gestáo, financiamento e influências de outros países (E40).

Contribuíram ao demonstrarem os problemas que decorrem das pesquisas que se utilizam de referenciais metodológicos e/ou analíticos descolados dos referenciais epistemológicos que estão subjacentes (E45).

Possibilita ao pesquisador um repertório e conhecimento que o auxilia a fazer escolhas teórico-metodológicas (E90).

Estas disciplinas contribuíram para a delimitação do objeto, no aprofundamento teórico, na elaboração de conceitos, na metodologia, na construção da minha pesquisa, tanto no processo de descoberta, quanto no processo de exposição dessas descobertas (E103).

Outra questão estava relacionada à existência ou não de disciplina ou discussóes relacionadas à ética na pesquisa e suas implicações para a pesquisa em Política Educacional. Cinquenta e um por cento responderam que não tiveram disciplina ou discussóes e 49\% responderam afirmativamente. Do total de 108 questionários, 19\% informaram que enfrentaram dilemas éticos no processo de pesquisa e $81 \%$ responderam que não tiveram. Os principais dilemas éticos referiam-se às seguintes questóes: anonimato, utilização de dados de acesso público, dificuldades para obtençáo do retorno de transcriçóes enviadas a entrevistados, proximidade (envolvimento) com os sujeitos da pesquisa, e dificuldades de acesso às informaçóes e para atender às exigências dos Comitês de Ética em Pesquisa. Segundo os respondentes, tais dilemas foram resolvidos com o auxílio do orientador e, algumas vezes, dos membros das bancas.

Com relação à definição do referencial teórico-epistemológico para a pesquisa da tese, os participantes responderam que tal definição ocorreu a partir de lei- 
turas individuais (25); sessôes de orientação (23); GP (14); disciplinas do programa (8); revisão de literatura (6); seminários (3); estudos e experiências anteriores (3); doutorado sanduíche (2); formação política e sindical e militância (2); desde o TCC (graduação); e curso de especialização (2). Observa-se a importância das sessões de orientação, dos GP, da revisão de literatura, bem como do estudo individual. Alguns respondentes (3) destacaram a importância da experiência anterior e da formação política e sindical e da militância e alguns, o caráter processual dessa definição:

O referencial teórico-epistemológico foi definido no decurso das orientaçóes individuais e teve como critério de seleção a capacidade de explicar o objeto investigado, ou seja, fez-se a opçáo pelo referencial teórico que apresentou os melhores caminhos de aproximação da realidade (considerando o recorte da pesquisa) e, consequentemente, de produção das respostas possíveis ao problema perquirido. Destarte, a análise empírica foi balizada pelos pressupostos teóricos da sociologia compreensiva tendo como principal interlocutor o conjunto da obra de Max Weber, o qual subsidiou o debate acerca da administração burocrática e do éthos que distingue os papéis e as relaçôes de poder entre os dois atores internos ao aparelho de Estado: o político e o burocrata (E31).

Juntamente com meu orientador, através de leituras que utilizassem lentes complexas para analisar os fenômenos educacionais. Ao longo da pesquisa, incorporei novos referenciais, tendo em vista que os dados coletados não podiam ser analisados com as lentes teóricas do projeto de tese (E5).

Fiz um levantamento do campo. Identifiquei as principais filiaçóes teóricas na área de avaliação educacional, consequentemente, da área de avaliaçấo da educação superior. Subsidiado pela cadeira de fundamentos, que paguei no doutorado, fiz um quadro de referencial teórico com as várias concepçôes de avaliação, presentes nas práticas avaliativas desenvolvidas nas políticas educacionais de avaliação. Depois fiz o mesmo procedimento com as concepçóes de regulaçẫo (E3).

\section{Considerações finais}

Apesar de constituir-se como um estudo exploratório e de pequena escala, a pesquisa traz elementos para a compreensão da formação e algumas implicações para o processo de formação de pesquisadores para a Política Educacional:

- Faz-se necessário desenvolver pesquisas mais abrangentes sobre a natureza do doutorado em Educação no Brasil (culturas de formação), bem como sobre as políticas e práticas a ele relacionadas;

- A prevalência do modelo de habilidades genéricas (do modelo pedagógico de desempenho de Bernstein) na formação do pesquisador de Políti- 
cas Educacionais necessita ser questionada. Os modos genéricos não são meros procedimentos pedagógicos econômicos de aquisição, mas se baseiam em um novo conceito de "trabalho" e de "vida", uma ideia que bem poderia ser chamada de "algo destinado ao curto prazo" (BERNSTEIN, 1998, p. 88). Dos modos genéricos, espera-se "que concretizem todo o seu potencial de flexibilidade e transferência, não se limitando apenas a desempenhos específicos" (BERNSTEIN, 1998, p. 88); assim, são totalmente estruturados no conceito de "capacitaçáo" (BERNSTEIN, 1998, p. 88). O modo genérico tende a não garantir o desenvolvimento de habilidades e práticas mais relacionadas ao próprio campo (Política Educacional) e àquelas destinadas em "longo prazo": o domínio teórico-epistemológico mais amplo, em um modelo de formação expandida (modelo de competência), o pensamento crítico, a capacidade de análise e a resoluçáo de problemas e comunicação. $\mathrm{O}$ fato de as LP caracterizarem-se por certo hibridismo e interdisciplinaridade as enriquecem, ampliando as possibilidades dos debates teórico-metodológicos. No entanto, aprofundar questóes mais específicas da pesquisa da área da Política Educacional é também necessário para manter um vínculo com o campo específico;

- Um desafio importante para a área é a criação de um projeto de formação orgânico, articulado e consciente. De modo geral, entendemos que esse projeto necessita incluir aspectos essenciais, tais como o estudo da Epistemologia, da metodologia da pesquisa, tecnologias de pesquisa, da redação acadêmica (habilidades genéricas), da ética na pesquisa, mas também o estudo mais aprofundado de questóes mais diretamente relacionadas ao campo da Política Educacional: epistemologias da Política Educacional, referenciais teóricos para a análise de políticas, história da constituição do campo, entre outros. As relaçōes entre aspectos gerais e específicos são fluidas e dinâmicas (CROSSOUARD, 2013) e devem objetivar a integração entre a aquisição de virtudes intelectuais que são necessárias no processo de pesquisa e elaboração da tese, ao invés de oferecer uma formação dissociada do desenvolvimento da pesquisa.

Estudos recentes sobre a pesquisa da área de Política Educacional (MAINARDES, 2017, 2018a) têm mostrado que se trata de um campo fortemente influenciado pelo pluralismo (estratégias de teorização combinada), com um potencial relevante para responder a seus problemas. No entanto, observa-se também o emprego de estratégias de teorização adicionada e ausência de teorização, cuja adequação e validade têm sido criticadas. Além disso, esses estudos indicam que a maioria das pesquisas tendem a se enquadrar nos níveis de análise e descrição, com um número significativamente menor de estudos de compreensão (MAINARDES \& TELLO, 2016). Tais tendências estão relacionadas a fatores associados à cultura e tradição de pesquisa no 
Brasil, financiamento para pesquisas, características do trabalho docente em universidades públicas e privadas, mas também às características do modelo de formação de pesquisadores em curso no Brasil no atual momento histórico.

\section{Notas}

1. Disponível em: <www.relepe.org $>$.

2. Para Hey (2008, p. 15), "campo acadêmico é o lócus de relaçốes, tendo como protagonistas agentes que têm por delegação produzir conhecimento acadêmico, isto é, um tipo de prática social legitimada e reconhecida como tal".

3. Segundo dados da Capes (BRASIL, 2017), do total de 74 PPGE com mestrado e doutorado em funcionamento em 2017, 44 eram de universidades públicas. Do total de 5.989 doutorandos matriculados, 4.726 eram de instituiçóes públicas $(78,91 \%)$. Do total de 1.342 titulados (doutorado), 1.038 eram de universidades públicas (77,34\%).

4. Para Bourdieu e Wacquant (2012, p. 274), o ofício de pesquisador é um modus operandi e um habitus. A formação do habitus cientifico é complexa, pois envolve "traduzir problemas altamente abstratos a operações científicas totalmente práticas", o que pressupôe uma relação muito peculiar com o que ordinariamente se chama de "teoria" e "empiria". Assim, não há outra maneira de dominar os princípios fundamentais de uma prática (e a prática da pesquisa científica não é uma exceção) que não a de praticá-los junto com um guia ou "treinador" que dê segurança e tranquilidade (BOURDIEU \& WACQUANT, 2012).

5. A discussão sobre gramáticas forte e fraca é complexa e polêmica. Moore e Muller (2003, p. 1.348) explicam que "a sociologia da educação é, então, uma estrutura de conhecimento horizontal com uma gramática fraca, com uma sintaxe conceitual incapaz de gerar descriçôes empíricas precisas e sem ambiguidades. E como essa gramática não consegue relacionar as descrições empíricas com as descrições teóricas sem controvérsias, a descrição empírica não pode arbitrar disputas conceituais. Consequentemente, quando surgem disputas, uma nova linguagem especializada é invariavelmente criada porque não existe um princípio geralmente aceito para integrar as teorias em disputa existentes. Do mesmo modo, não existem meios geralmente aceitos para se livrar das velhas teorias antiquadas que começam a estorvar a literatura”.

6. A respeito da constituição do campo da Política Educacional no Brasil e das características das LP em PPGE, ver Stremel (2016).

7 E: egresso.

\section{Referências}

BERNSTEIN, B. A pedagogização do conhecimento: estudos sobre recontextualização. Cadernos de Pesquisa, São Paulo, n. 120, p. 75-110, nov. 2003. http://dx.doi. org/10.1590/S0100-15742003000300005 
BERNSTEIN, B. Pedagogía, control simbólico e identidad. Madri: Ediciones Morata, 1998.

BERNSTEIN, B. Vertical and horizontal discourse: an essay. British Journal of Sociology of Education, v. 20, n. 2, p. 153-173, 1999. https://doi.org/10.1080/01425699995380

BOURDIEU, P. Homo academicus. Florianópolis: Editora da UFSC, 2011.

BOURDIEU, P.; WACQUANT, L. Una invitación a la sociología reflexiva. Buenos Aires: Siglo Vintiuno, 2012.

BRASIL. Coordenação de Aperfeiçoamento de Pessoal de Nível Superior (Capes). GeoCapes. SistemadeInformaçôesGeorreferenciadasdaCapes.Distribuiçãodediscentesdepós-graduaçáo no Brasil. 2017. Disponível em: <https://geocapes.capes.gov.br>. Acesso em: 30 ago. 2018.

CROSSOUARD, B. M. Conceptualising doctoral researcher training through Bernstein's theoretical frameworks. International Journal for Researcher Development, v. 4, n. 2, p. 72-85, 2013. https://doi.org/10.1108/IJRD-05-2013-0007

CROSSOUARD, B. M. The (re-)positioning of the doctorate through the eyes of newly qualified researchers. Twenty First Century Society, v. 5, n. 3, p. 197-214, 2010. https:// doi.org/10.1080/17450144.2010.498524

DEEM, R.; BREHONY, K. J. Doctoral students' access to research cultures-are some more unequal than others? Studies in Higher Education, v. 25, n. 2, p. 149-165, 2000. https://doi.org/10.1080/713696138

GOROSTIAGA, J. M. La formación de investigadores en el campo de la política educativa: una mirada regional. Revista de la Educación Superior, v. 46, n. 183, p. 37-45, 2017. https://doi.org/10.1016/j.resu.2017.06.001

HEY, A. P. Esboço de uma sociologia do campo acadêmico: a Educação Superior no Brasil. São Carlos: EdUFSCar, 2008.

HOSTINS, R. C. L. Formação de pesquisadores em programas de excelência de pósgraduação em educação. Revista Brasileira de Educaçáo, Rio de Janeiro, v. 18, n. 53, p. 415-434, abr./jun. 2013. http://dx.doi.org/10.1590/S1413-24782013000200010

HOSTINS, R. C. L. Formação de pesquisadores na Pós-Graduação em Educação: embates ontológicos e epistemológicos. 176 f. 2006. Tese (Doutorado em Educação) Universidade Federal de Santa Catarina, Florianópolis, 2006.

MAINARDES, J. A pesquisa no campo da política educacional: perspectivas teóricoepistemológicas e o lugar do pluralismo. Revista Brasileira de Educaçáo, Rio de Janeiro, v. 23, p. 1-20, 2018a. http://dx.doi.org/10.1590/s1413-24782018230034

MAINARDES, J. A pesquisa sobre política educacional no Brasil: análise de aspectos teórico-epistemológicos. Educaçáo em Revista, Belo Horizonte, v. 33, p. 1-25, 2017. http://dx.doi.org/10.1590/0102-4698173480

MAINARDES, J. Reflexóes sobre o objeto de estudo da política educacional. Laplage em Revista, Sorocaba, v. 4, n. 1, p. 186-201, jan./abr. 2018b. https://doi.org/10.24115/ $\underline{\text { S2446-6220201841399p.186-201 }}$ 
MAINARDES, J.; TELLO, C. A pesquisa no campo da política educacional: explorando diferentes níveis de abordagem e abstração. Arquivos Analíticos de Políticas Educativas, v. 24, n. 75, p. 1-16, 2016. http://dx.doi.org/10.14507/epaa.24.2331

MERGA, M. K. Educational Researchers, Training of. In: FREY, B. The SAGE Encyclopedia of educational research, measurement, and evaluation. Thousand Oaks: SAGE Publications, 2018. p. 573-574.

MOORE, R.; MULLER, J. O crescimento do conhecimento e a lacuna discursiva. Educaçáo \& Sociedade, Campinas, v. 24, n. 85, p. 1319-1340, set./dez. 2003. http:// dx.doi.org/10.1590/S0101-73302003000400012

MORAIS, A. M. Basil Bernstein: Sociologia para a educação. In: TEODORO, A.; TORRES, C. A. (orgs.). Educaçáo crítica e utopia: perspectivas para o século XXI. Sáo Paulo: Cortez, 2004. p. 83-94.

MOWBRAY, S.; HALSE, C. The purpose of the PhD: theorising the skills acquired by students. Higher Education Research \& Development, v. 29, n. 6, p. 653-664, 2010. https://doi.org/10.1080/07294360.2010.487199

PATRUS, R.; LIMA, M. C. A formação de professores e de pesquisadores em Administração: contradiçóes e alternativas. Economia \& Gestáo, Belo Horizonte, v. 14, n. 34, p. 4-29, jan./mar. 2014. https://doi.org/10.5752/P.1984-6606.2014v14n34p4

STREMEL, S. A constituição do campo acadêmico da política educacional no Brasil. 312 f. 2016. Tese (Doutorado em Educação) - Universidade Estadual de Ponta Grossa, Ponta Grossa, 2016.

TELLO, C. La enseñanza de la Política Educativa y la formación de investigadores en el campo. Entre las matrices históricas y la episteme de época. Revista de Educaçáo Pública, Cuiabá, v. 24, n. 55, p. 125-151, jan./abr. 2015a. http://dx.doi.org/10.29286/rep.v24i55.2169

TELLO, C. (org.). Los objetos de estudios de la política educativa: hacia una caracterización del campo teórico. Ciudad Autónoma de Buenos Aires: Autores de Argentina, 2015b. Disponível em: <http://relepe.org/images/libros/Tello\%20Los\%20 objetos $\% 20 \mathrm{de} \% 20$ estudio $\% 20 \mathrm{de} \% 20 \mathrm{la} \% 20$ pol $\%$ C3\%ADtica $\% 20 \% 20$ educativa.pdf $>$. Acesso em: 02 jun. 2018.

TELLO, C.; MAINARDES, J. Revisitando o enfoque das epistemologias da política educacional. Práxis Educativa, Ponta Grossa, v. 10, n. 1, p. 153-178, 2015. http://dx.doi. org/10.5212/PraxEduc.v.10i1.0007

Recebido em 14 de junho de 2018.

Aceito em 05 de outubro de 2018. 